\title{
Chemical Ionization Pathways of Polyfluorinated Chemicals- A Connection to Environmental Atmospheric Processes
}

\author{
David A. Ellis and Scott A. Mabury \\ Department of Chemistry, Toronto University, Toronto, Ontario, Canada
}

\begin{abstract}
A systematic mass spectrometry study of an industrially prolific class of polyfluorinated compounds known as telomers was conducted. The study specifically focused upon polyfluorinated alcohols along with corresponding saturated and $\alpha, \beta$-unsaturated fluoroacids. Within each class differing fluoroalkyl chain length homologues were investigated, using negative and positive chemical ionization mass spectrometry ( $\mathrm{NCI}$ and $\mathrm{PCI}$ ). In the case of the fluoroalcohols, NCI resulted in the production of more elaborate spectra than the other classes. Moreover, it showed the interesting production of $\mathrm{HF}_{2}^{-}$and the complex of this species, along with $\mathrm{F}^{-}$, with the parent molecule. These complexes resulted in the formation of the novel $\mathrm{H}_{2} \mathrm{~F}_{3}^{-}$ion. Results show that there is significant intra-molecular hydrogen bonding that occurs for these compounds, which influences the molecules fragmentation. This bonding will also influence the fate and disposition through environmental processes (e.g., $\mathrm{V}_{\mathrm{P}}, \mathrm{k}_{\mathrm{OH}}, \mathrm{K}_{\mathrm{OW}}, \mathrm{K}_{\mathrm{OA}}$ ) which are affected by molecular geometry. Furthermore, there is an increased accumulation and persistence potential for the molecule as a function of the fluorocarbon chain length. We have shown that in conjunction with the use of mass spectroscopy the engertics of environmental processes for polyfluorinated materials can be established. (J Am Soc Mass Spectrom 2003, 14, 1177-1191) (@ 2003 American Society for Mass Spectrometry
\end{abstract}

$\mathrm{M}$ ultiple fluorination of organic materials often imparts thermodynamic structural resistance to degradation within a molecule. The degree of fluorination would be expected to have an effect upon the magnitude of this resistance. From an environmental standpoint, little is known about the environmental persistence of a chemical class relative to the degree of fluorination. Research concerning the persistence of polyfluorinated compounds has focused almost entirely on the fate of fluorinated acids [1,2]. The major acids which have been investigated are trifluoroacetic acid (TFA), 1-perfluorooctanoic acid (PFOA), and 1-perfluorooctanesulfonic acid (PFOS). These are two carbon and eight carbon alkanoic acids, respectively. The studies that have been made thus far show extreme environmental persistence, with no significant abiotic or biotic processes yet observed [1, 2]. Furthermore, a study conducted by Martin et al. has demonstrated that the propensity for bioaccumulation is greatly enhanced as a function of increasing the fluoro-carbon chain length of these compounds [3]. Thus, a method for

Published online August 11, 2003

Address reprint requests to Dr. S. A. Mabury, Department of Chemistry, University of Toronto, 80 St. George St., Toronto, Ontario M5S 3H6, Canada. E-mail: smabury@chem.utoronto.ca analyzing and assessing their potential abiotic fate as a function of fluorination would be an asset.

The use of fluorinated compounds is widespread, finding synthetic applications in a multitude of broad and diverse applications, from blood substitutes to agrochemicals. The quantities of fluorinated compounds manufactured for use has steadily increased over recent decades, a trend that is expected to continue in the foreseeable future [4].

The introduction of fluorine within organic molecules can lead to interesting changes in physical properties. In fact, it has been stated that, "as a substituent, it is rarely boring, always good for a surprise, but often completely unpredictable" [5]. This is especially true where the effects upon physical properties are concerned [6]. For example, it has been shown that polyfluorinating an alkyl chain results in a rigid rod-like structure whose carbon-carbon conformation changes as chain length increases, the change occurring between 8-12 carbons, 8 carbons being a zigzag conformation, 10 both zigzag and helical and 12 fully helical [7]. This results in interesting trends in physical properties, e.g., when comparing the boiling point of perfluorocarbons to that of their hydrocarbon counterparts it can be seen that the fluorocarbons have a lower boiling point despite having much larger masses and secondly, that there is an inflection point in the rate of change in 


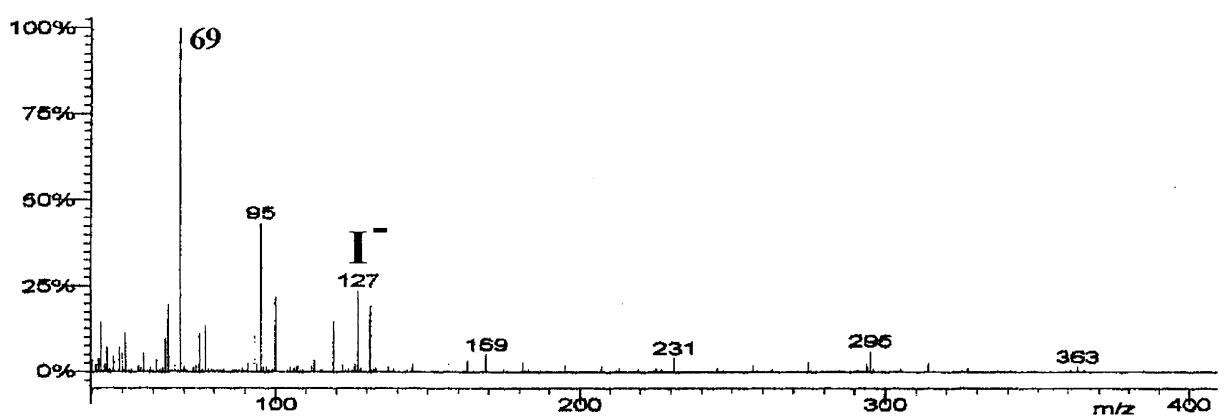

Figure 1. A typical electron impact mass spectrum. The spectrum for the $6: 2$ telomer alcohol is shown.

boiling point when the carbon chain length increases beyond 8 carbons. The incorporation of fluorine can also have the effect of increasing and decreasing other bond energies within the molecule. For example, $\alpha$-fluorination markedly increases the bond strengths of $\mathrm{C}-\mathrm{F}$ and $\mathrm{C}-\mathrm{O}$ bonds but does not alter the strength of $\mathrm{C}-\mathrm{H}$, $\mathrm{C}-\mathrm{Cl}$, or $\mathrm{C}-\mathrm{Br}$ bonds. $\beta$-Fluorination significantly decreases $\mathrm{C}-\mathrm{H}$ bond strengths, but has little effect on $\mathrm{C}-\mathrm{F}$ bonds [8]. It would therefore seem reasonable to assume that the behavior of such species in analysis techniques that rely on the physical properties of the molecule, such as the thermodynamics of bonding and the geometry of the molecule, may produce unique or unforeseen results, e.g., the techniques of gas chromatography or mass spectrometry.

Environmental measurement of molecules that have a large degree of fluorination has been the subject of increased interest in the past few years [9-15]. Invariably, the method of choice for analysis has been mass spectrometry, with the exception of the occasional use of ${ }^{19} \mathrm{~F}$ NMR. [16, 17]. To date there have been relatively few systematic mass spectroscopic investigations of polyfluorinated compounds despite its continued use both as a quantitative and qualitative method of analysis [18-21]. In general, these studies have focused on the use of electron impact ionization which reportedly yields a low abundance of molecular ions [19]. A few studies have also investigated the use of electron capture ionization techniques, for example in the studies of semifluorinated alkanes and that for perfluorocyclohexanes and decalanes [19, 22]. Using electron capture ionization, Napoli et al. observed the sequential loss of HF for hydrofluorocarbons and attributed it to the interaction of the hydrocarbon chain with the fluorocarbon portion [18]. In the case of perfluorocarbons only molecular ions were seen when NCI was employed with no subsequent cleavage of the fluorocarbon chain observed.

The fluorinated sub-class of compounds that were of interest in the present investigations were telomer alcohols and acids. These telomer alcohols and acids comprise a perfluorinated alkyl chain, $\mathrm{F}\left(\mathrm{CF}_{2} \mathrm{CF}_{2}\right)_{n}$ in which $n=2,4,6$, or 8 , which in turn is connected to either an ethanolic $\left(-\mathrm{CH}_{2} \mathrm{CH}_{2} \mathrm{OH}\right)$ or ethanoic $\left(-\mathrm{CH}_{2} \mathrm{C}[\mathrm{O}] \mathrm{OH}\right)$ functional group. These compounds derive their name from the process that is used for their manufacture, telomorization, which generally results in the production of polyfluorocarbon chains with an even number of carbon atoms. This class of compounds is denoted by a numbering system, $n: m$, where $n$ is the number of carbons that are fluorinated and $\mathrm{m}$ is the number of hydrogenated carbons. The telomer alcohols are used in a variety of commercial materials including the surface treatment of paper and textiles and as intermediates in the synthesis of other fluorinated organics [23]. Oxidation of the telomer alcohols leads to the production of species that we have described as telomer acids. We hypothesize that these acids might be expected to be produced through biotic and abiotic oxidation of the parent alcohol in the environment.

The telomer alcohols have been observed and quantitated in the atmosphere using GC-MS(CI) [12]. Martin et al. showed that these compounds often gave complex and unusual fragmentation patterns. For this reason we have attempted to elucidate and characterize these fragmentations. With the aid of structural changes, we have attempted to ascertain variations in molecular properties, for example, trends in the molecular thermodynamics such as relative bond dissociation energies and tortional angles within the molecule. These properties in turn may be of assistance in elucidating environmental breakdown processes, persistence and transport phenomena.

\section{Materials and Methods}

Unless otherwise stated all materials were used as purchased without further purification. The telomer alcohols $(>97 \%)$ shown in Figure 1 were purchased from Fluorochem USA (West Columbia, SC). All other chemicals used were purchased from Aldrich Chemical Company (Mississauga, Canada). The polyfluorinated acids (Table 1) were synthesized by a method similar to that reported by Achilefu et al. [24]. A brief outline of the procedure is given here. $1.2 \mathrm{~g}$ of the appropriate 2-fluoroalkyl ethanol was dissolved in a $10 \mathrm{~mL}$ acetone- $5 \mathrm{~mL}$ diethylether solution and placed in a roundbottomed flask equipped with a magnetic stirring bar. $10 \mathrm{~mL}$ of a freshly prepared solution of Jones Reagent was added slowly to the solution using a pressure 
Table 1. The chemical structures of the Telomer analytes

\begin{tabular}{|c|c|c|}
\hline Telomer alcohols & Telomer acids & Telomer $\alpha \beta$-unsaturated acids \\
\hline $\mathrm{CF}_{3}\left(\mathrm{CF}_{2}\right)_{n} \mathrm{CF}_{2} \mathrm{CH}_{2} \mathrm{CH}_{2} \mathrm{OH}$ & $\stackrel{\mathrm{O}}{\|} \mathrm{CF}_{3}\left(\mathrm{CF}_{2}\right)_{n} \mathrm{CF}_{2} \mathrm{CH}_{2} \mathrm{COH}$ & 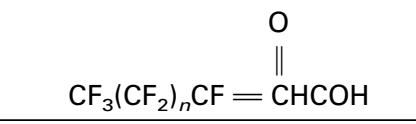 \\
\hline $\begin{array}{l}n=2(4: 2)^{*} \\
n=4(6: 2) \\
n=6(8: 2) \\
n=8(10: 2)\end{array}$ & $\begin{array}{l}n=2(4: 2 \mathrm{~A}) \\
n=4(6: 2 \mathrm{~A}) \\
n=6(8: 2 \mathrm{~A}) \\
n=8(10: 2 \mathrm{~A})\end{array}$ & $\begin{array}{l}n=2(4: 2 \cup A) \\
n=4(6: 2 \cup A) \\
n=6(8: 2 \cup A) \\
n=8(10: 2 \cup A)\end{array}$ \\
\hline
\end{tabular}

*Acronyms are given for each in parenthesis.

equilibrating dropping funnel with constant stirring. The Jones Reagent was added until a persistent red color resulted in the reaction mixture. The reaction solution was extracted using three $25 \mathrm{~mL}$ portions of ether. The combined organic extracts were washed with $50 \mathrm{~mL}$ of water followed by drying over $\mathrm{Na}_{2} \mathrm{SO}_{4}$. The organic phase was concentrated under reduced pressure to yield the acids as white crystalline solids. The products were then crystallized from $\mathrm{CCl}_{4}$ to yield products with identical spectroscopic properties, e.g., ${ }^{13} \mathrm{C},{ }^{19} \mathrm{~F}$, and ${ }^{1} \mathrm{H} \mathrm{NMR}$, as that reported in the literature [24].

The synthesis of the $\alpha, \beta$-unsaturated acids shown in Table 1 was conducted using the following procedure. $750 \mathrm{mg}$ of the previously synthesized acid was placed in $20 \mathrm{~mL}$ of THF. To this was added $5 \mathrm{~mL}$ of $2 \mathrm{M} \mathrm{NaOH}$ and the resulting solution stirred for $2 \mathrm{~h}$. At this point, the solution was extracted with three $25 \mathrm{~mL}$ portions of ether, which were subsequently combined and dried over $\mathrm{MgSO}_{4}$ (anh.). The organic extracts were concentrated under reduced pressure to yield crystalline white solids. The products were then recrystallized from $\mathrm{CCl}_{4}$ to yield products again with identical properties to those reported in the literature [24].

Full scan mass spectra were recorded using a Micromass (Manchester, UK) 70-250S (double focusing) mass spectrometer. Sample introduction was conducted by use of a solids probe. Unless otherwise noted the source temperature was $250{ }^{\circ} \mathrm{C}$ for both $\mathrm{CI}$ and EI. The accelerating voltage was $8 \mathrm{keV}$ and the EI electron energy was $70 \mathrm{eV}$. For CI spectra, methane was used as an ionizing gas with an estimated source pressure of 0.2 mbar.

High Resolution Mass Spectra were obtained using a Micromass 70-250S (double focusing) spectrometer in negative EI mode. Data were obtained at 10,000 (10\% valley) resolution. For GC-MS analysis aqueous samples were acidified and extracted with ethyl acetate.

MS/MS spectra were recorded using a Varian (Mississauga, Canada) CP-3800 gas chromatograph equipped with a J \& W $60 \mathrm{~m}, 0.25 \mathrm{~mm}, 0.5 \mu \mathrm{m}, \mathrm{DB}-35$ column and Varian Saturn 2000 ion trap mass analyzer using helium as a collision gas $(1 \mathrm{~mL} / \mathrm{min})$.

GC-MS(NCI) were conducted using Perkin-Elmer (Woodbridge, Canada) GC Auto System XL equipped with a Turbomass quadrupole mass spectrometer with a $30 \mathrm{~m}, 0.25 \mathrm{~mm}$ ZB-35 column (Phenominex, Mississauga, Canada). The carrier gas was helium at a flow rate of $0.5 \mathrm{~mL} / \mathrm{min}$. The oven temperature program was $60{ }^{\circ} \mathrm{C}$ for $2 \mathrm{~min}$, followed by a temperature ramp of 10 ${ }^{\circ} \mathrm{C} / \mathrm{min}$ to a $200{ }^{\circ} \mathrm{C}$, and then $30^{\circ} \mathrm{C} / \mathrm{min}$ to a $150{ }^{\circ} \mathrm{C}$, and finally $40{ }^{\circ} \mathrm{C} / \mathrm{min}$ to a $300{ }^{\circ} \mathrm{C}$.

For ${ }^{13} \mathrm{C},{ }^{1} \mathrm{H}$ and ${ }^{19} \mathrm{~F}$ NMR, all spectra were obtained at $25^{\circ} \mathrm{C}$ on a Varian Unity 500, 3 channel spectrometer operating at the nuclei appropriate frequency.

\section{Results and Discussion}

Electron impact mode for the mass spectral identification and quantitation of the fluoro telomers proved to be problematic due to a lack of analyte specific fragments. An example of this is shown in Figure 1, where it can be seen that only a small molecular fragment is observed. Furthermore, fragments $131 \quad\left(\mathrm{C}_{3} \mathrm{~F}_{5}\right), 95$ $\left(\mathrm{C}_{3} \mathrm{H}_{2} \mathrm{~F}_{3}\right.$, obtained by HRMS) and $69\left(\mathrm{CF}_{3}\right)$ were observed for all fluoroalcohol analytes. We therefore sought softer chemical ionization techniques in order to identify and perhaps quantify these potential environmental pollutants, in conjunction with the systematic study of the interesting and novel fragmentation patterns observed for polyfluoroalcohols.

The electron capture and Brønsted acid chemical ionization mass fragments of the fluoro acids and alcohols that were investigated are presented in Tables 2 and 3. Representative mass spectra of the $6: 2$ series for both negative and positive chemical ionization modes are presented in Figure 2. Initial comparisons of these mass spectra to those obtained for their hydrogenated counterparts, e.g., a comparison of octanol and octanoic acid NCI spectra with those obtained for the $6: 2$ alcohol and 6:2A (cf. Figures 2 and 3), indicate an enhanced complexity for the fluorinated analogues. At first sight this might appear to be contrary to what would be expected given that fragmentation processes such as the loss of $\mathrm{HF}$ compared with $\mathrm{H}_{2}$ are effectively thermolytically equivalent [25]. The behavior, and hence prediction, of the mass spectra of polyfluroinated materials, when compared to their hydrocarbon counter parts, appears to be fraught with difficulty. The incorporation of fluorine within the molecule can impart interesting thermodynamic properties that in turn can lead to more, or less, complex spectra than their hydrocarbon 
Table 2. NCI-MS of telomer compounds

\begin{tabular}{ll}
\hline Compound & \multicolumn{1}{c}{ Fragment ions (relative height \%) } \\
\hline \hline $4: 2$ & $303(17.3) 283(16.9) 263(8.2) 223(24.1) 204(28.1) 194(11.2) 184(100.0)$ \\
$6: 2$ & $174(68.3) 164(81.4) 156(22.4) 146(24.3) 136(22.4)$ \\
& $403(15.5) 383(14.8) 363(5.9) 323(23.2) 304(26.3) 294(8.9) 284(100.0)$ \\
$8: 2$ & $274(62.1) 264(79.0) 256(25.1) 246(14.3) 236(27.1)$ \\
& $503(8.7) 483(6.0) 463(2.0) 423(12.8) 404(28.9) 394(2.0) 384(100.0)$ \\
$10: 2$ & $374(44.0) 364(81.5) 356(39.6) 346(9.7) 336(52.7)$ \\
$4: 2 A$ & $603(7.3) 583(3.7) 563(1.0) 523(7.3) 504(18.7) 494(2.7) 484(100.0)$ \\
$6: 2 A$ & $474(28.8) 464(77.9) 456(50.5) 446(9.0) 436(66.6)$ \\
$8: 2 A$ & $277(81.7) 257(23.7) 238(96.7) 218(100.0) 194(49.6) 174(73.6) 63(9.4)$ \\
$10: 2 A$ & $377(33.6) 357(10.4) 338(81.2) 318(51.0) 294(21.1) 274(100.0) 63(10.1)$ \\
$4: 2 U A$ & $477(13.1) 457(4.4) 438(45.1) 418(19.5) 394(9.1) 374(100.0)$ \\
$6: 2 U A$ & $577(43.0) 557(16.1) 538(46.6) 518(10.4) 494(7.0) 474(100.0)$ \\
$8: 2 U A$ & $257(64.9) 238(94.0) 218(100.0) 194(78.4) 174(95.6)$ \\
$10: 2 U A$ & $357(67.3) 338(89.6) 318(60.3) 294(26.6) 274(100.0)$ \\
\hline
\end{tabular}

analogues. It has been noted that the relative position of the fluorine atom to a carbanionic center can result in a net stabilization or destabilization of the charge due to inductive effects $(-\mathrm{I} \sigma)$ or non-bonding electron donation $(-\mathrm{I} \pi)$ respectively [26]. For example, a fluorine atom will stabilize a negative charge located at a $\mathrm{sp}^{3}$ hybrid carbon and destabilize it on an $\mathrm{sp}^{2}$ hybrid carbon and always stabilize a negative charge located $\beta$ to it. A further complication has been attributed to enhanced steric interactions between the fluorine atoms of an anionic intermediate when compared with hydrogens [26]. These effects have been witnessed in the mass spectra of fluorinated analogues of hydrocarbons [18, 19]. For example, it has been stated that under electron impact conditions, $\mathrm{C}_{6} \mathrm{~F}_{13} \mathrm{CH}_{2} \mathrm{COOR}$ esters undergo completely different fragmentation patterns due to the perfluorinated tail, leading to the authors conclusion that $\mathrm{CF}_{2}-\mathrm{CF}_{2}$ enhanced bond strengths simplify the spectra [18, 19]. However, in the same study, the electron impact spectra of polyfluorinated alcohols were shown to be more complex than expected due to interactions between the hydroxyl hydrogen and the fluorinated chain. In a further study conducted on polyfluorinated hydrocarbons it was shown that there is an unexpected, enhanced stability of the $\mathrm{CF}_{2}-\mathrm{CH}_{2}$ bridge which in turn results in no fragmentation at this point in the molecule [18]. In the case of these systems, loss of HF was only observed when the hydrocarbon portion of the chain exceeded $8 \mathrm{CH}_{2}$ units. In general, Napoli et al. concluded that polyfluorination leads to a thermodynamic strengthening of the alkyl chain, which results in a suppression of fragmentation processes due to chain cleavages when compared to their hydrocarbon analogues, however fragmentation process are enhanced when there is an interaction of the functional group with the fluorocarbon tail [18].

\section{Mass Spectrometry of Fluorinated Alcohols}

\section{Negative Chemical Ionization Pathways for Fluorinated Alcohols}

In order to elucidate the fragmentation channels for the telomer alcohols (Table 1), an NCI mass spectrum of a non-telomer alcohol, $\mathrm{F}\left(\mathrm{CF}_{2}\right)_{7} \mathrm{CH}_{2} \mathrm{OH}$ (7:1 alcohol), was obtained as this compound has a similar, yet more simplistic, mass spectrum as a result of having one less- $\mathrm{CH}_{2}$-unit (Figure 4). As shown in Scheme 1, it is believed that a percentage of the alcohol molecules first

Table 3. PCI-MS of telomer compounds

\begin{tabular}{ll}
\hline Compound & \multicolumn{1}{c}{ Fragment ions (relative height \%) } \\
\hline \hline $4: 2$ & $265(100.0) 227(80.5)$ \\
$6: 2$ & $365(100.0) 327(73.2)$ \\
$8: 2$ & $465(100.0) 427(59.1)$ \\
$10: 2$ & $565(100.0) 527(67.7)$ \\
$4: 2 A$ & $279(19.9) 259(100.0) 241(24.1) 213(30.9) 195(22.5) 175(48.0)$ \\
$6: 2 A$ & $379(31.5) 359(100.0) 341(28.1) 313(49.5) 295(30.5) 275(80.0)$ \\
$8: 2 A$ & $479(38.1) 459(100.0) 441(28.9) 413(31.3) 395(21.1) 375(40.2)$ \\
$10: 2 A$ & $579(40.3) 559(92.3) 541(32.3) 513(64.2) 495(22.7) 475(100.0)$ \\
$4: 2 U A$ & $259(100.0) 241(26.6) 213(20.5) 195(15.9) 175(42.1)$ \\
$6: 2 U A$ & $359(100.0) 341(29.2) 313(21.4) 295(11.7) 275(29.1)$ \\
$8: 2 U A$ & $459(100.0) 441(34.7) 413(63.1) 395(29.4) 375(81.6)$ \\
$10: 2 U A$ & $559(100.0) 541(33.2) 513(62.8) 495(25.3) 475(73.0)$ \\
\hline
\end{tabular}



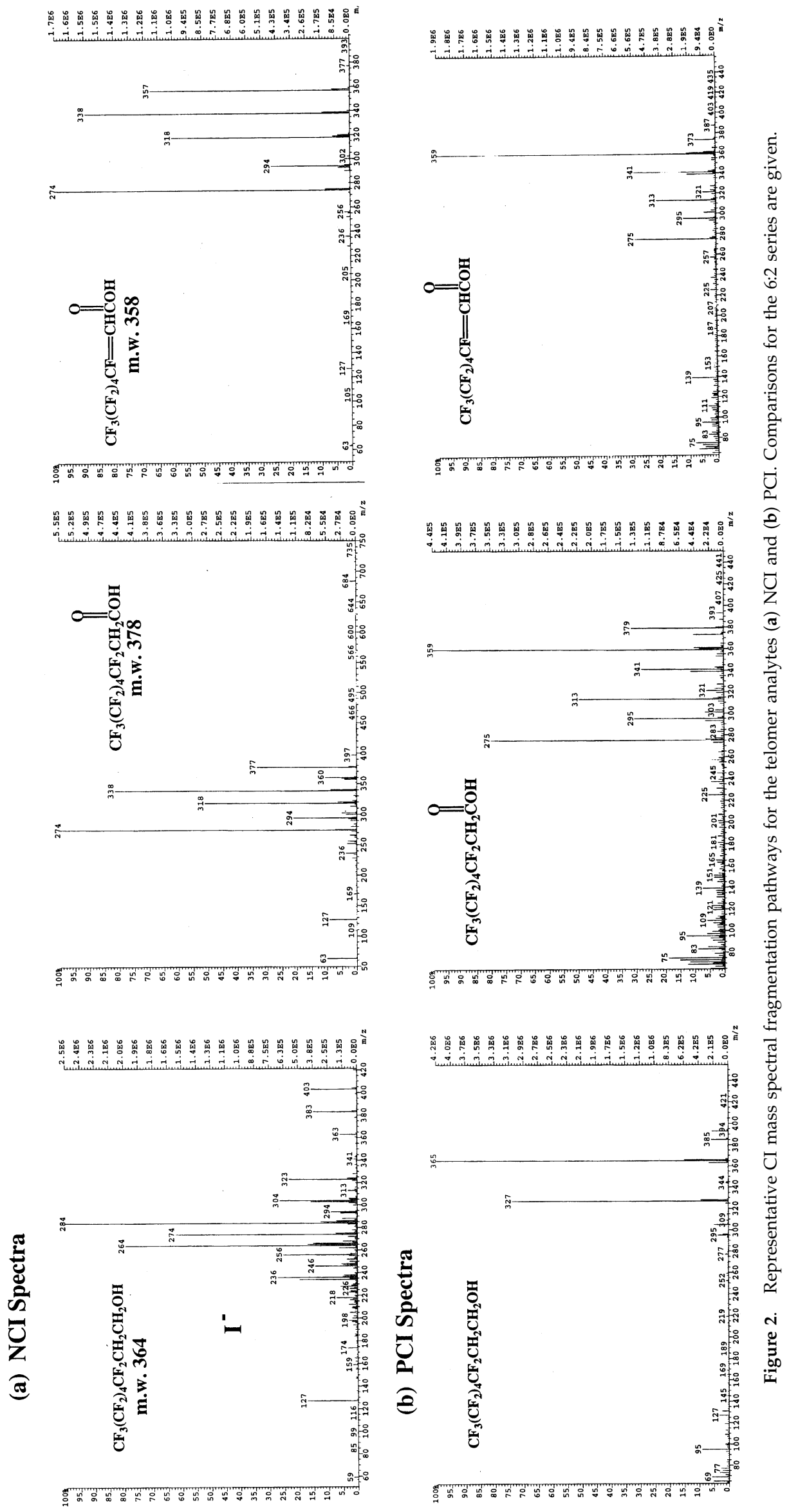

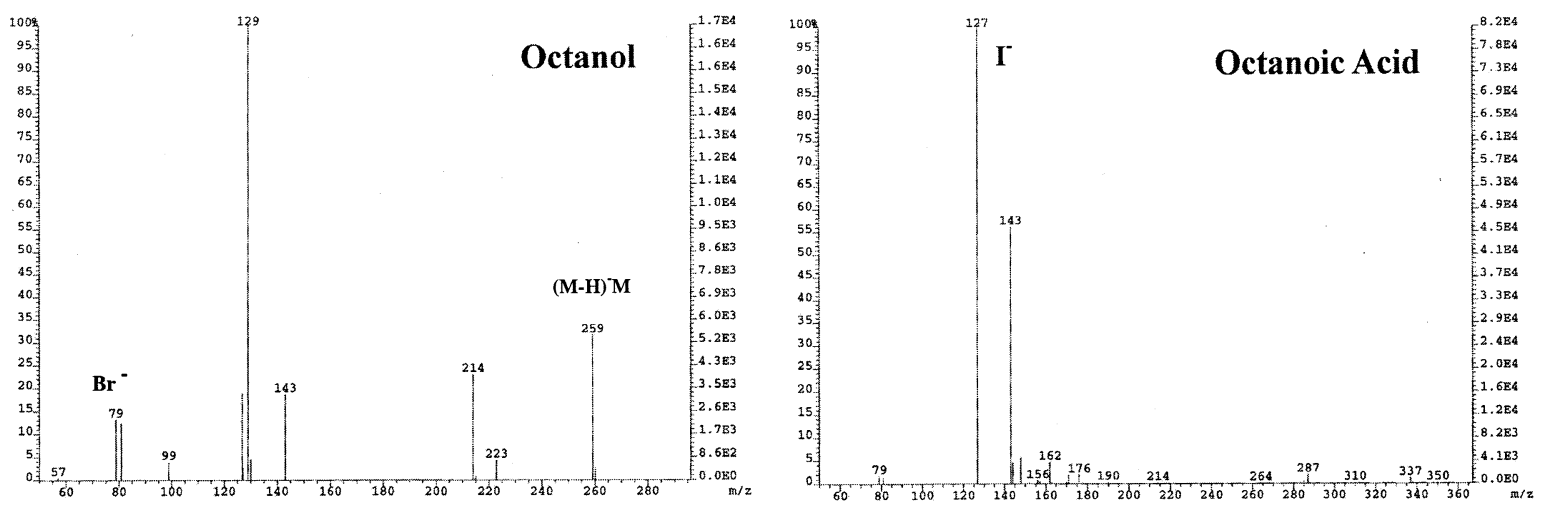

Figure 3. Comparsion NCI spectra of octanol and octanoic acid.

undergo dissociative electron capture to produce $\mathrm{F}^{-}$, a process that is common for fluorinated materials [27]. An alcohol molecule is then observed to complex with the $\mathrm{F}^{-}$in a fashion similar to that shown by Brauman et al. [28] to yield RO·HF ${ }^{-}$as evidenced by the $[\mathrm{M}+19]^{-}$ ion. The $[\mathrm{M}+19]^{-}$ion then either undergoes loss of HF to yield an [M -1$]$ ion or it complexes with a neutral alcohol molecule to yield an $[\mathrm{M}+399]^{-}$ion. This dimer ion was not seen for the telomer alcohols using the same source pressures and mass as in the study of the 7:1 alcohol. In contrast to the monomer fragmentation, the molecular ion of the dimer appears to be stabilized yielding the base peak in the dimer fragmentation. However, it does not appear that this dimer has an effect upon the fragmentation pattern of the $[\mathrm{M}-1]^{-}$ ion, i.e., the fragments which arise from the $[\mathrm{M}-1]^{-}$ ion, $\leq 399 \mathrm{~m} / \mathrm{z}$ are not a result of the dimer fragmenting in any fashion which is different to the monomer. It is worth noting however that the $[\mathrm{M}+399]^{-}$ion also undergoes similar fragmentation to that of the [M $1]^{-}$.

The telomer alcohols, in comparison to the 7:1 alcohol, do not appear to undergo any appreciable dimerization. This is likely due to decreased hydrogen bonding between molecules which results from the decreased acidity of the $-\mathrm{OH}$ group when the $\mathrm{CF}_{2}$ moiety is in the $\beta$ position rather than the $\alpha$ position

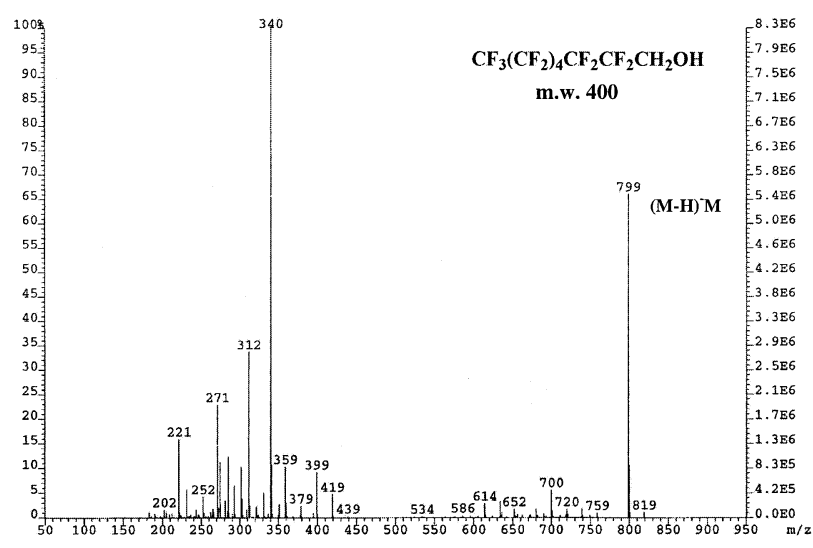

Figure 4. NCI spectrum for $\mathrm{F}\left(\mathrm{CF}_{2}\right)_{7} \mathrm{CH}_{2} \mathrm{OH}$ (7:1 alcohol). relative to it. This electronic effect also has a reasonably pronounced affect upon the fragmentation pattern, although a good deal of similarity still occurs between the two. As expected, the NCI mass spectra are more complex for the fluorinated telomer alcohols (Table 2, Figures 2a and 4) than the 7:1 alcohol.

The initial fragmentation pathway hypothesized for the 6:2 alcohol is given in Scheme 2. Key to the fragmentation of these alcohols appears to be intramolecular hydrogen bonding, which is indicated in the scheme. Although the exact structure of this cyclic intermediate requires further investigation, there is a good deal of supportive literature for the invoking of such a geometry. For example, other researchers, in the case of hydrofluorocarbons, have invoked a six membered back bonding transition state between the hydrocarbon portion of the chain and the fluorocarbon portion to support the sequential loss of HF in similar systems [18]. Previous x-ray crystallographic studies suggest that the perfluoro portion of the molecular chain adopts a ridged zigzag geometry with the end hydrocarbon segment of the chain folding back on top of that fluorinated portion [7, 29]. The use of massanalyzed ion kinetic energy (MIKE) spectroscopy in the study of semifluorinated alkanes (e.g., $\left.\mathrm{F}\left(\mathrm{CF}_{2}\right)_{8}\left(\mathrm{CH}_{2}\right)_{8} \mathrm{H}\right)$ allowed for the observation of $\left[\mathrm{M}-\mathrm{HF}^{+}{ }^{+}\right.$and this, in conjunction with the use of an electron capture technique using acetone, showed the sequential loss of up to ten neutral HF units depending upon the length of the chain being investigated. It was concluded that loss processes were not occurring through a heterolytic bond cleavage and it would appear that the mechanism of HF elimination in this system is concerted [18]. Napoli et al. concluded that such a sequence of losses necessitates extensive interaction between the hydrocarbon and fluorocarbon portions of the chain. They also showed that there was no evidence for the cleavage of the $\mathrm{CF}_{2}-\mathrm{CH}_{2}$ bond within the molecule and suggested that the unusually high stability of this bond could be explained by a H-F bridging interaction.

Such intramolecular interaction in the case of telomer alcohols in the liquid phase is supported by the studies conducted by Von Werner and Wrackmeyer [30]. They 


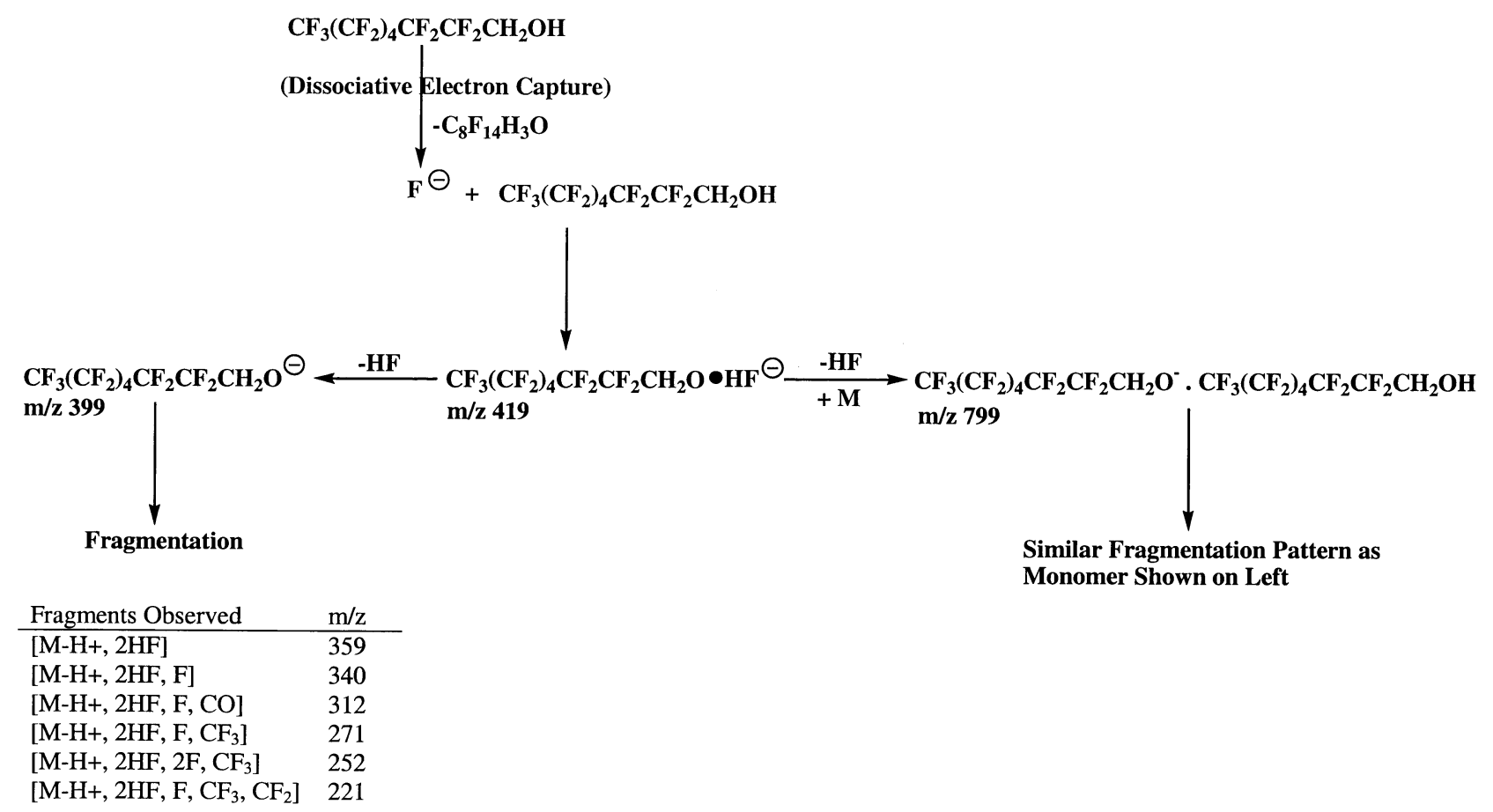

Scheme 1. Principal modes of ionization and fragmentation pathways for $\mathrm{CF}_{3}\left(\mathrm{CF}_{2}\right)_{6} \mathrm{CH}_{2} \mathrm{OH}$.

showed that fluorination in the $\beta$ position to a $\mathrm{CH}_{2} \mathrm{OH}$ group had a marked effect on the ${ }^{13} \mathrm{C}$ NMR chemical shift while having little effect upon the $\alpha \mathrm{CH}_{2}$, an effect which has been assigned to the hyperconjugative interaction of the lone pair of electrons of the fluorine at that carbon. In later studies Von Werner and Wrackmeyer [31] also employed ${ }^{17} \mathrm{O}$ NMR and showed that electron density at the oxygen is increased as observed through the oxygen shielding effect. This strongly suggests that the terminal ethanolic group is closely associated with the fluorocarbon portion of the molecule.

The fragmentation pathway shown in Scheme 2 is given for the 6:2 alcohol, but is identical and representative of the process that occurs for the other telomer alcohols. As was the case for the 7:1 alcohol, the 6:2 molecule can under go initial dissociative electron capture to produce $\mathrm{F}^{-}$. The $\mathrm{F}^{-}$ion then complexes with a neutral molecule of telomer alcohol. This complex then undergoes neutral loss of $\mathrm{HF}$ or loss of $\mathrm{HF}_{2}^{-}$. Due to the novel interaction of the $\mathrm{OH}$ with the fluorocarbon chain, once the $\mathrm{F}^{-}$complexes with it there is also the ability for loss of the $\mathrm{HF}_{2}^{-}$, hydrogen difluoride. This reaction is thermodynamically favorable, with an energy of $38.6 \mathrm{kcal} / \mathrm{mol}$, [27] and at sufficient gas pressures the naked $\mathrm{HF}_{2}^{-}$ion is observed in the spectra $(\mathrm{m} / \mathrm{z}$ 39) (Figure 5). If $\mathrm{HF}_{2}^{-}$were indeed produced, one would expect the molecule to act in a similar fashion toward neutral telomer alcohol molecules as $\mathrm{F}^{-}$did, i.e., to complex to it. Indeed an $[\mathrm{M}+39]^{-}$ion is observed, and furthermore was always observed irrespective of the ionizing gas pressure. According to Caldwell and Kebarle, gas phase $\mathrm{HF}_{2}^{-}$can react with $\mathrm{HF}$ to produce $\mathrm{H}_{2} \mathrm{~F}_{3}^{-}$, dihydrogentrifluoride $(30.9 \mathrm{kcal} / \mathrm{mol}) .{ }^{27}$ Thus, if the hypothesized mechanism is correct and $\mathrm{HF}_{2}^{-}$is indeed complexing with the telomer in the same fashion as $\mathrm{F}^{-}$, and the postulation that the $\mathrm{F}-\mathrm{HF}$ interaction is the process by which $\mathrm{HF}_{2}^{-}$is formed, then the formation of $\mathrm{H}_{2} \mathrm{~F}_{3}^{-}$through a $\mathrm{F}-\mathrm{H}-\left(\mathrm{HF}_{2}^{-}\right)$interaction would also occur. Indeed, $\mathrm{H}_{2} \mathrm{~F}_{3}^{-}, \mathrm{m} / z 59$, is observed and is seen quite clearly in the spectrum given in Figure 5. The 7:1 alcohol appears to yield a very small amount of an $[\mathrm{M}$ $+39]^{-}$ion suggesting that through bending it can also adopt similar geomeries, but generally the telomer alcohol's intra-molecular hydrogen bonding is unique to their structure and essential in the fragmentation pathways observed. It is believed that this is the first observation of the production adducts with $\mathrm{HF}_{2}^{-}$in the mass spectrometric analysis of fluorinated compounds. Although its occurrence in the literature is reasonably sparse, $\mathrm{HF}_{2}^{-}$itself has been previously observed in the unimolecular decomposition of the mono-fluoroethylene radical anion when produced by an electron attachment process of the parent molecule [32]. In our study, $\mathrm{HF}_{2}^{-}$production was observed for each of the fluorinated alcohols investigated. It is interesting to note that it was not observed in the fragmentation of fluorinated acids, although it is recognized that this may be due to a lack of complexation of the species with the acid rather than it not being formed. The production of $\mathrm{H}_{2} \mathrm{~F}_{3}^{-}$ appears to be even more novel, in terms of mass spectrometry, as it has only ever been reported once in literature concerning the identity of products in a high voltage point-to-point corona discharge [33].

When comparing the fragmentation of the 6:2 with that for 7:1 alcohol, it can be seen that the $[\mathrm{M}-1]^{-}$ions can undergo fragmentation through a similar channel, 


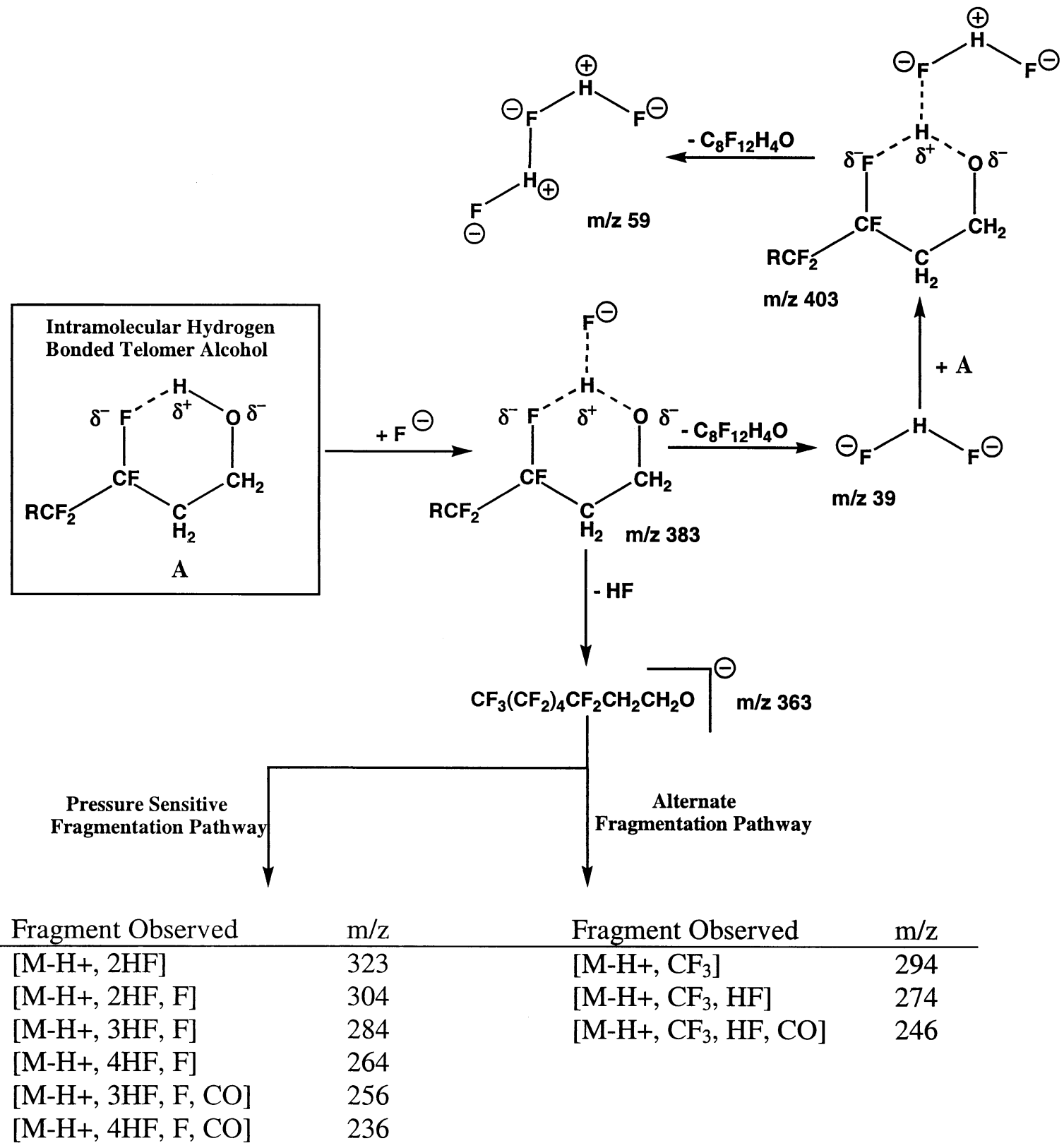

Scheme 2. The hypothesized fragmentation pathways for the $6: 2$ telomer alcohol in NCI mode ( $\mathrm{R}=$ $\left.\mathrm{CF}_{3}\left(\mathrm{CF}_{2}\right)_{3}\right)$. The essential cyclic intramolecular hydrogen bonded geometry of the alcohol (inset) is shown. The pathway leading to the production of the novel compounds, hydrogen difluoride $(\mathrm{m} / \mathrm{z} 39)$ and dihydrogentrifluoride $(m / z 59)$ is indicated.

namely the apparently concerted loss of two HF units followed by the loss of a $\mathrm{F}$ atom. This channel then continues with the loss of two further units of HF $(\mathrm{m} / \mathrm{z}$ 284 and 264), an option obviously not available to the 7:1 alcohol. Loss of CO is then observed following the loss of either of the two HF units to yield a species that is not observed to undergo any further fragmentation. Fragmentation of the telomer alcohols by this channel ultimately leads to the same suit of products as the 7:1 channel, that is stripping all hydrogens and oxygen from the molecule to yield a perfluoro-radical carbanion.
A further interesting aspect of our observed telomer fragmentation process is that the sequential loss of the third and forth set of HF units appears to be extremely pressure sensitive (Figure 6), thus quantification using these ions $(\mathrm{m} / \mathrm{z} 264,274$, and 284) should be avoided. No such pressure dependence was observed for the 7:1 alcohol.

An alternate channel that also appears available to the $6: 2$ alcohol $[\mathrm{M}-1]^{-}$ion is fragmentation through the initial loss of a $\mathrm{CF}_{3}$ unit. $\mathrm{CF}_{3}$ loss was also seen for the 7:1 alcohol, although at a later stage in the fragmentation process. The loss of $\mathrm{CF}_{3}$ from the $[\mathrm{M}-1]^{-}$ion of 


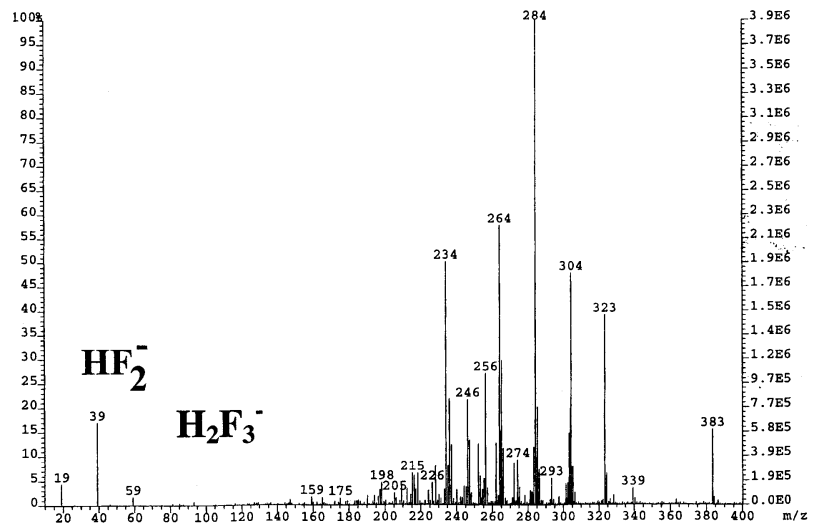

Figure 5. NCI mass spectrum for the $6: 2$ alcohol showing the production of $\mathrm{HF}_{2}^{-}$and $\mathrm{H}_{2} \mathrm{~F}_{3}^{-}$.

the $6: 2$ alcohol is likely due to the loss of HF being less favorable relative to the $7: 1$, again due to the enhanced acidity of the $\mathrm{H}^{\prime} \mathrm{s}$ in the latter case. Loss of $\mathrm{CF}_{3}$ is then followed, interestingly, by loss of only one unit of HF. Next, the loss of CO, presumably accompanied by the migration of hydrogen in a similar fashion to that shown by Napoli et al. occurs, to yield a product that still contains three hydrogen atoms within the structure [19].

\section{Fragmentation Pattern for the Fluorinated Alcohols Using Positive Chemical Ionization}

In contrast to the results obtained for the alcohols using negative chemical ionization, the positive ionization mode yields far more simplistic spectra (Table 3 and Figure 2b). The alcohols first undergo a typical proton transfer reaction with the ionizing gas, with hydride abstraction non-evident (likely due to the enhanced $\mathrm{C}-\mathrm{H}$ bond strength; an effect of the fluorine chain as discussed earlier). A fragment corresponding to the loss of $\mathrm{HF}+\mathrm{H}_{2} \mathrm{O}$ was observed from the $\mathrm{M}+\mathrm{H}$ molecular ion (Scheme 3). Further fragmentation of the molecule and its subsequent fragmentation pattern was conducted using $\mathrm{MS}^{\mathrm{n}}$ upon the daughter ion $[\mathrm{M}-38]^{+}$ (Scheme 3). The simultaneous loss of $\mathrm{HF}$ and $\mathrm{H}_{2} \mathrm{O}$ from the chain in preference to the unimolecular loss of $\mathrm{H}_{2} \mathrm{O}$ is unusual [34] and the thermodynamic reasons for this unique loss remain to be investigated, although it is likely that it is again due to the intra-molecular hydrogen bonding which appears to occur. It is further hypothesized that the driving force may lie in the release of tortional angle strain within the molecule. For example, it is known that the intramolecular geometry of the fluorocarbon chain alters as the chain length is increased from 8 to 12 carbon atoms in an effort to release internal strain [7]. This is consistent with the observation that the relative intensity of the fragment corresponding to this loss does not alter with increasing fluorocarbon chain length for $\mathrm{C} 4-\mathrm{C} 8$, but then increases again at C10 (Table 3, Figure 9). This is also in accordance with a change in internal geometry of the molecule. It is interesting to note, however, that for the 7:1 alcohol only $\mathrm{H}_{3} \mathrm{O}^{+}$is lost from the chain in PCI mode in comparison with the telomer alcohols, which is further

\section{2 mbar Methane Pressure}

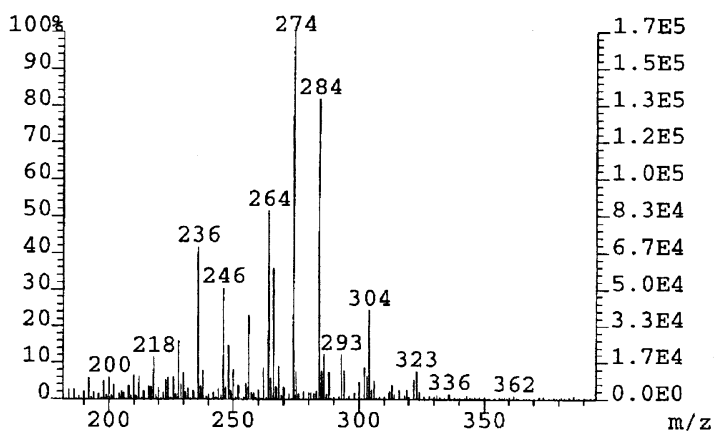

\section{2 mbar Methane Pressure}

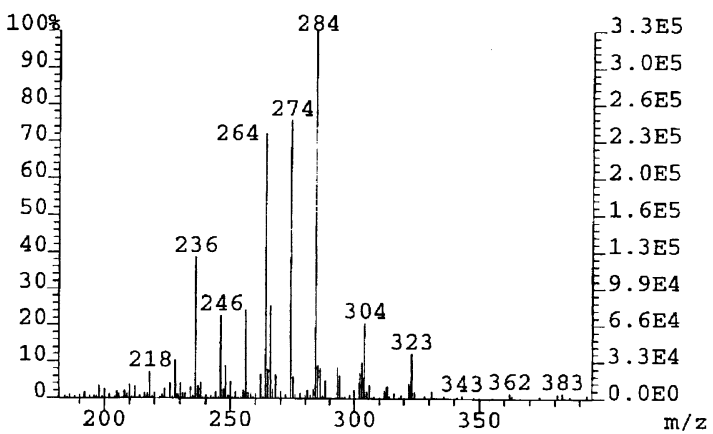

\subsection{2 mbar Methane Pressure}

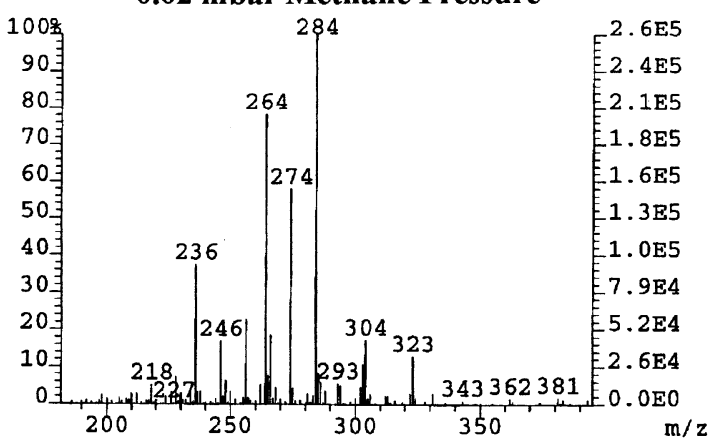

Figure 6. Effects of ionizing gas pressure (methane) on relative peak intensities for the 6:2 telomer alcohol. 


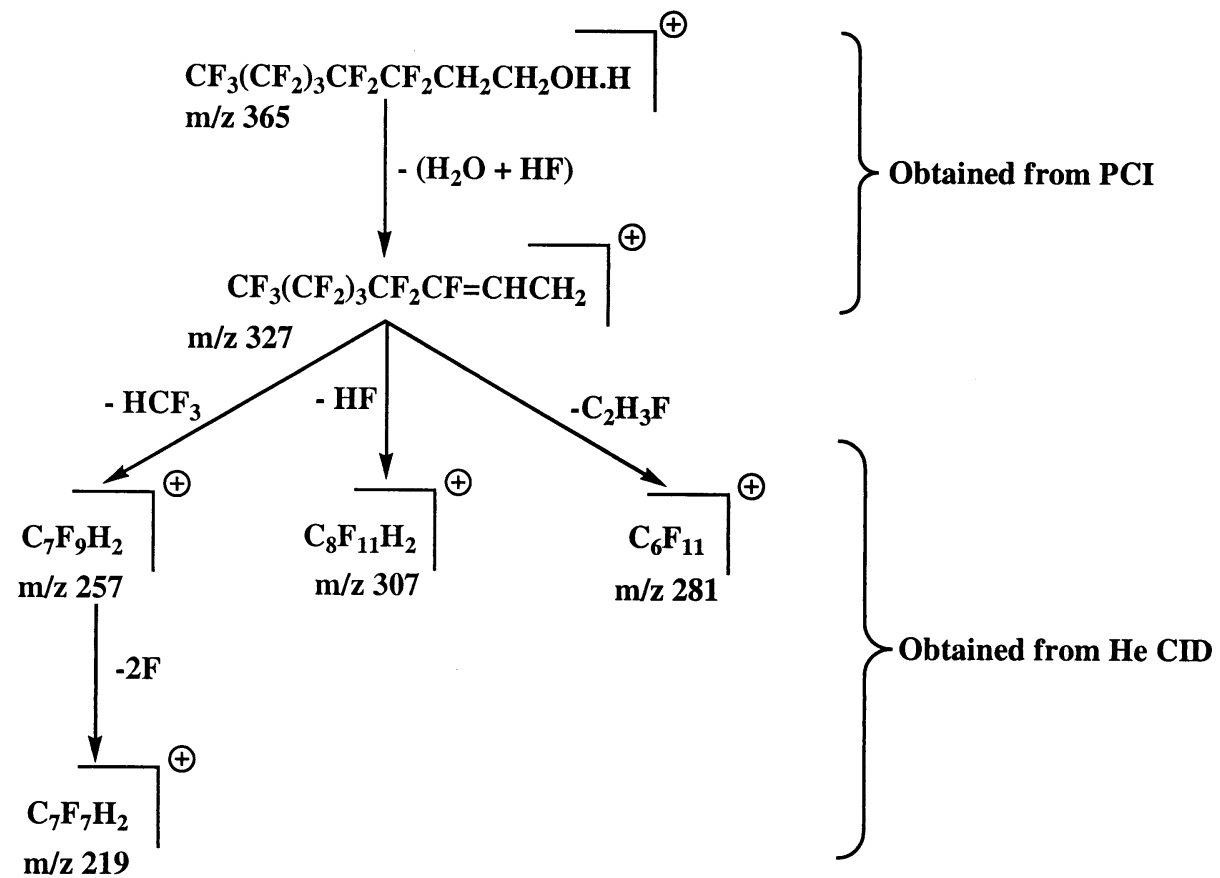

Scheme 3. The hypothesized fragmentation pattern for telomer alcohols in PCI and He CID modes.

evidence that the molecular geometry difference between the two is responsible for the difference in fragmentation pathways. Small amounts of a molecular ion gas adduct $\mathrm{C}_{2} \mathrm{H}_{5}$ is always seen for these molecules in this mode. This ion species does not, itself, appear to have any further unusual fragmentation associated with it and therefore does not seem to be detrimental to identification or quantification of the alcohol.

\section{Environmental Assessment of Mass Spectrometry Results for Telomer Alcohols}

The positive identification of cyclic intra-molecular hydrogen bonding in the telomer alcohols leads to the conclusion that all environmental processes governed by molecular geometry will be significantly affected as these novel geometries will impact the free energy of the process. Furthermore, it is believed that current modeling methods, which are based upon the structure or free energy relationships of a molecule, will have large uncertainty in their results due to the lack compensation being made for these geometrical features. The geometries associated with the compounds and the resultant effect that this imparts upon the physical properties may lead to novel and interesting chemistries in the atmospheric gas phase. For example, these results suggest that the telomer alcohols may have a close association, an association that one would not expect for alcohols, with tropospheric charged species and/or polar species as evidenced from their universal association with $\mathrm{F}^{-}$and $\mathrm{HF}_{2}^{-}$. The telomer alcohols have been observed as atmospheric pollutants [12]. Complexation with atmospheric components such as hydro- gen sulfate $\left(\mathrm{HSO}_{4}^{-}\right)$which has been observed in the nucleation of sulfuric acid, [36] or the charged surface of a particle, or with non-charged polar molecules such as water vapor, may affect their dissemination. Atmospheric lifetimes, for example reaction rates with tropospheric cleansing reagents, such as hydroxy radicals $(\mathrm{OH})$, may also be affected by such complexations. Predictive methods for the estimation of reaction rates with $\mathrm{OH}$ may be hampered because of these previously unforeseen molecular geomeries.

It would appear from the fragmentation of the telomer that the lowest energy pathway for the degradation of these compounds, either biotically or abiotically, would result in the production of stable polyflourometabolites which in turn might be expected to be environmentally persistent and hence accumulative.

From these results, it can be postulated that the electron density distribution associated with such unique structural geometries will impact physical properties such as vapor pressures, e.g., vapor pressures will be greater than expected from linear predictions based upon the molecules size and functional groups, which is indeed experimentally observed to be the case [35]. The unique differences in geometry of these molecules is also expected to influence physical properties of the molecules such as $\mathrm{K}_{\mathrm{ow}}$ and hence bioaccumulation. This postulation is supported by the recent observation that bioaccumulation potential increases tenfold for every additional $\mathrm{CF}_{2}$ unit within the alkyl chain for perfluoroacids [3]. From a purely thermodynamic standpoint, due to the ease of loss of fluorine, it would appear that as the fluorocarbon portion of the chain increases, $\mathrm{C} 4-\mathrm{C} 8$, there would be no significant change its de- 

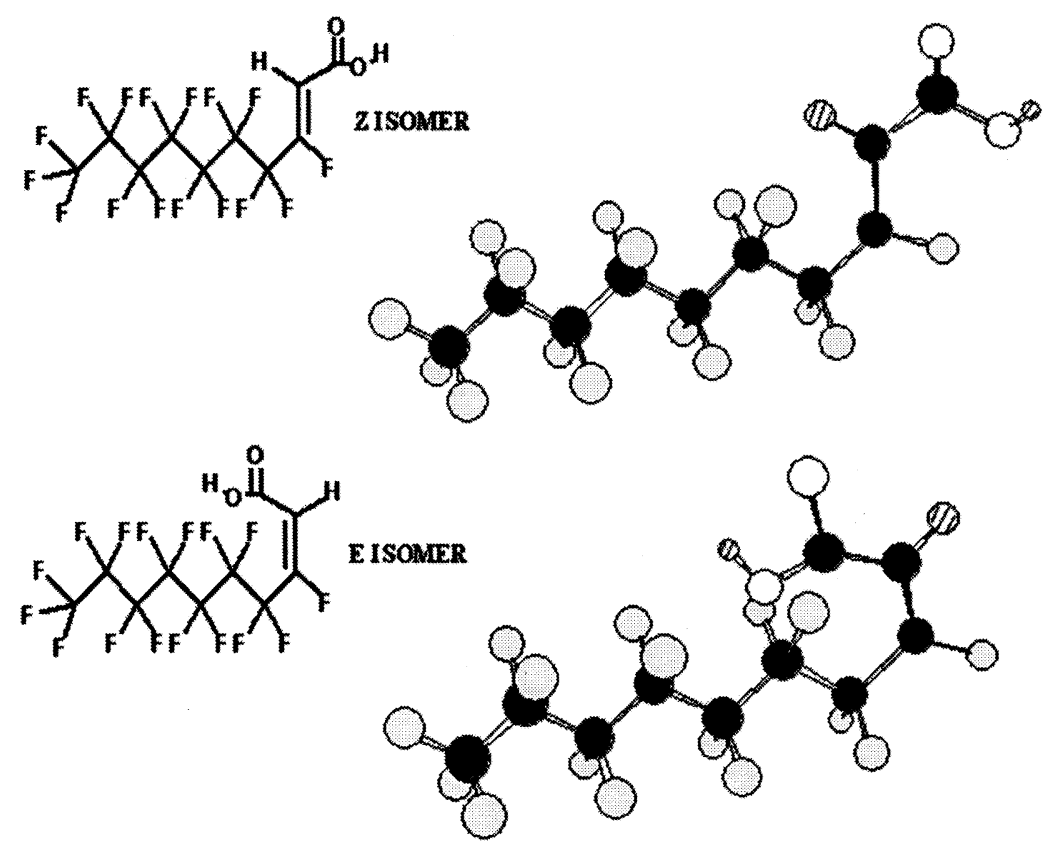

Fluorine $\bigcirc$ Carbon Hydrogen $\bigcirc$ Oxygen

Figure 7. Proposed geometry of telomer $\alpha \beta$-unsaturated acids geometrical isomers that lead to the fragmentation channels observed as outlined in Scheme 4.

gradability, thus no change in propensity for persistence. This, however, alters as the fluoro-chain is increased to 10 carbon atoms and greater and thus persistence would be expected to be greater.

\section{Mass Spectrometry of Fluorinated Acids \\ Fragmentation Pattern for the Fluorinated Acids Using Negative Chemical Ionization}

It is proposed that the fluorinated acids used in this study also adopt a similar geometry described for the telomer alcohols, i.e., the hydrocarbon portion of the molecule back bonding with the fluorocarbon portion the molecule. This geometry would then be enhanced with the $\alpha, \beta$-unsaturated acids relative to the acids due to the added rigidity of the double bond. A two and three-dimensional representation of this is given in Figure 7 . When these acids are synthesized, both the E and $\mathrm{Z}$ isomers are produced to differing degrees, presumably the $\mathrm{Z}$ isomer being thermodynamically favored over the $\mathrm{E}$ isomer due to steric hindrance between the fluorocarbon chain and the carboxylate group (Figure 7). It is hypothesized that the two isomers will vary in their fragmentation due to changes in the proximity of the carboxylate group and the fluorocar- bon chain. This hypothesis was verified by the analysis of the acids using GC-MS, in which the two isomers were separated and their mass spectra recorded. As indicated in Table 2, all of the saturated telomer acids undergo an initial loss of HF, presumably to form the $\alpha, \beta$-unsaturated acid, which then proceeds to fragment further. The acids ability to lose HF decreases as the fluorocarbon chain length increases (4:2UA-10:2UA) indicating a strengthening in the $\mathrm{C}-\mathrm{F}$ bond and/or changes in the mechanism and geomeries associated (Figure 8). For example, a change in geometry may causes an E2 type elimination to be unfavored due to the required $180^{\circ}$ torsional angle required between the atoms, resulting in a mechanism closer to that of an $\mathrm{E} 1_{\mathrm{cb}}$ pathway. The fragmentation pathway of the saturated acids is identical to the unsaturated acids after this initial loss. The overall fragmentation pathway is given in Scheme 4. As was the case for the alcohols there appears to be the formation of a fluoride ion through a dissociative electron capture mechanism. Fluoride is then observed to complex with a neutral molecule of acid, $[\mathrm{M}+19]^{-}$. There appears to be two different channels of fragmentation available to the parent molecule, and the channel that is taken depends upon the isomer. For the $\mathrm{E}$ isomer, the carbon of the carboxylate 


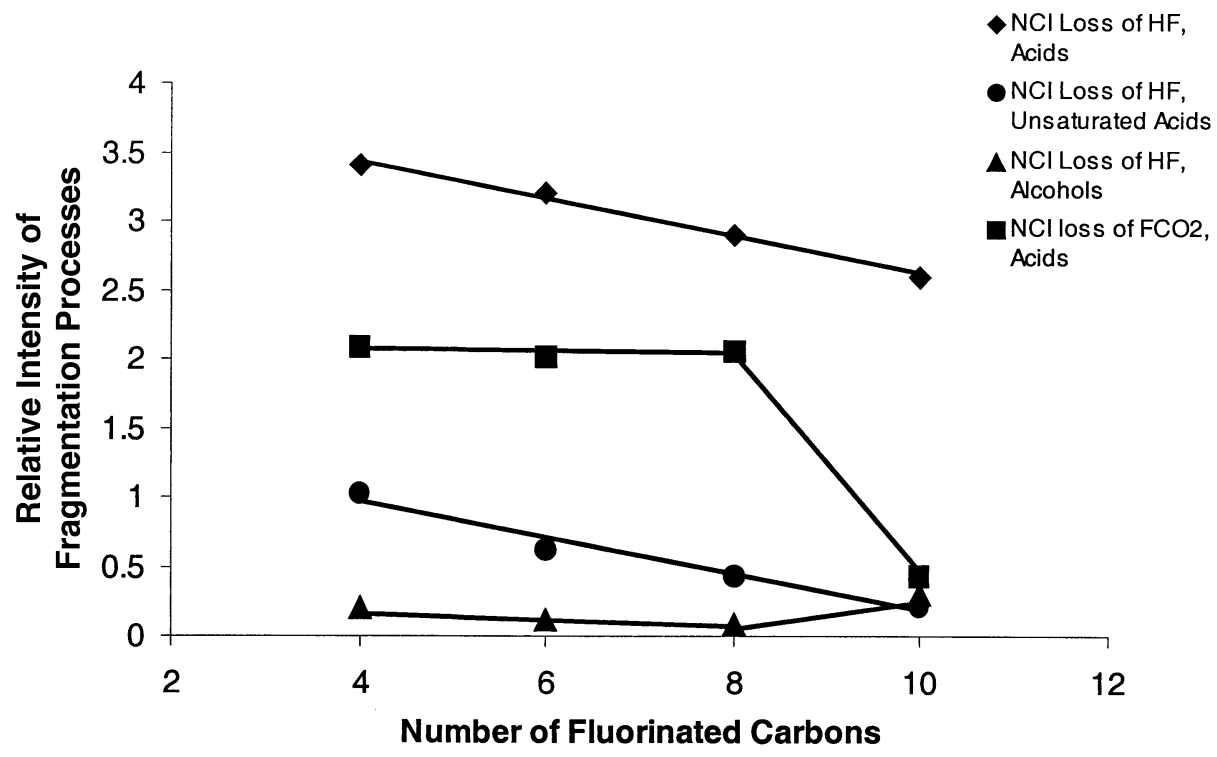

Figure 8. The ability for comparative loss process to occur as a function of fluorocarbon chain length. The relative intensity of the fragmentation process was calculated by expressing the abundance of the initial ion as a function of the fragment ion.

group would be held in close proximity to a fluorine atom on the backbone of the fluorocarbon chain that facilitates the loss of $\mathrm{FCO}_{2}$, evidenced by the presence of a 63 ion. This loss appears to occur with the same ease for 4-8 fluorocarbon chain lengths (i.e., 4:2A[UA]-8: $2 \mathrm{~A}[\mathrm{UA}])$ for both the acids and the unsaturated acids (Table 2). When the fluorocarbon chain length reaches a length of 10 carbon atoms, the loss of $\mathrm{FCO}_{2}$ is observed to be drastically reduced. This again is likely explained by the change in geometry of the fluorocarbon chain resulting in the loss of fluorine from the backbone of the molecule to be less favored. The loss of $\mathrm{FCO}_{2}$ is not seen for the $\mathrm{Z}$ isomer, instead the loss of fluorine alone occurs. HF is the next loss for both isomers followed by loss of $\mathrm{CO}_{2}$ for the $\mathrm{Z}$ isomer. Thus, overall, both isomers undergo the same elements of fragmentation, although through a different sequence of events, to yield the same final stable ion $[\mathrm{M}-103]^{-*}$, typically the base peak, which then undergoes no further observable fragmentation.

Unlike the telomer alcohols, the fragmentation pattern does not appear to be affected greatly by changes in the ionizing gas pressure. However, it was shown that optimal conditions for production of the molecular ion occur at lower source temperatures (Figure 9).

\section{Fragmentation Pattern for the Fluorinated Acids Using Positive Chemical Ionization}

As can be seen from the mass spectral data given in Table 3, the fragmentation patterns for the telomer acids in PCI mode are similar to those observed under negative chemical ionization processes. The channel, observed for the $\mathrm{Z}$ isomer, is essentially identical to that which was described in the previous NCI discussion.
However, there are important differences that occur for the E isomer. When comparing the NCI and PCI channels for the E isomer, it can be seen that the initial loss of HF in NCI mode is now replaced by the loss of water that is followed by a loss of $\mathrm{CO}$ rather than loss of $\mathrm{CO}_{2}$. It would then appear that no further fragmentation occurs, which is unlike NCI where both isomers eventually fragment to reach the same final species. This is likely due to the stabilization of the positive charge on terminal carbon by the vinyl bond; further loss of HF would be unfavorable due to the positive charge being located in an unfavorable terminal alkynyl position.

\section{Environmental Assessment of Mass Spectrometry Results for Telomer Acids}

Like the alcohols, the telomer acids appear to form six membered cyclic intra-molecularly hydrogen bonded geometries. As was discussed previously, this unique geometry is likely to affect any environmental process that is dependent upon molecular geometry. From the trends in the ability for loss of HF from the acid, it would suggest that hydrolytically the persistence of the acids would be proportional to the length of the fluorocarbon chain, the long chain being more persistent that the shorter chain. This would also have an impact upon biodegradation for pathways that yield the loss of HF.

\section{Fragmentation Pattern for the Fluorinated Compounds Using Ammonia Chemical Ionization}

Ionization of the fluorinated compounds was also conducted using ammonia CI. In the case of the acids [M + $\left.\mathrm{NH}_{4}^{+}\right]^{+}$ions were observed which, unlike in the case of 


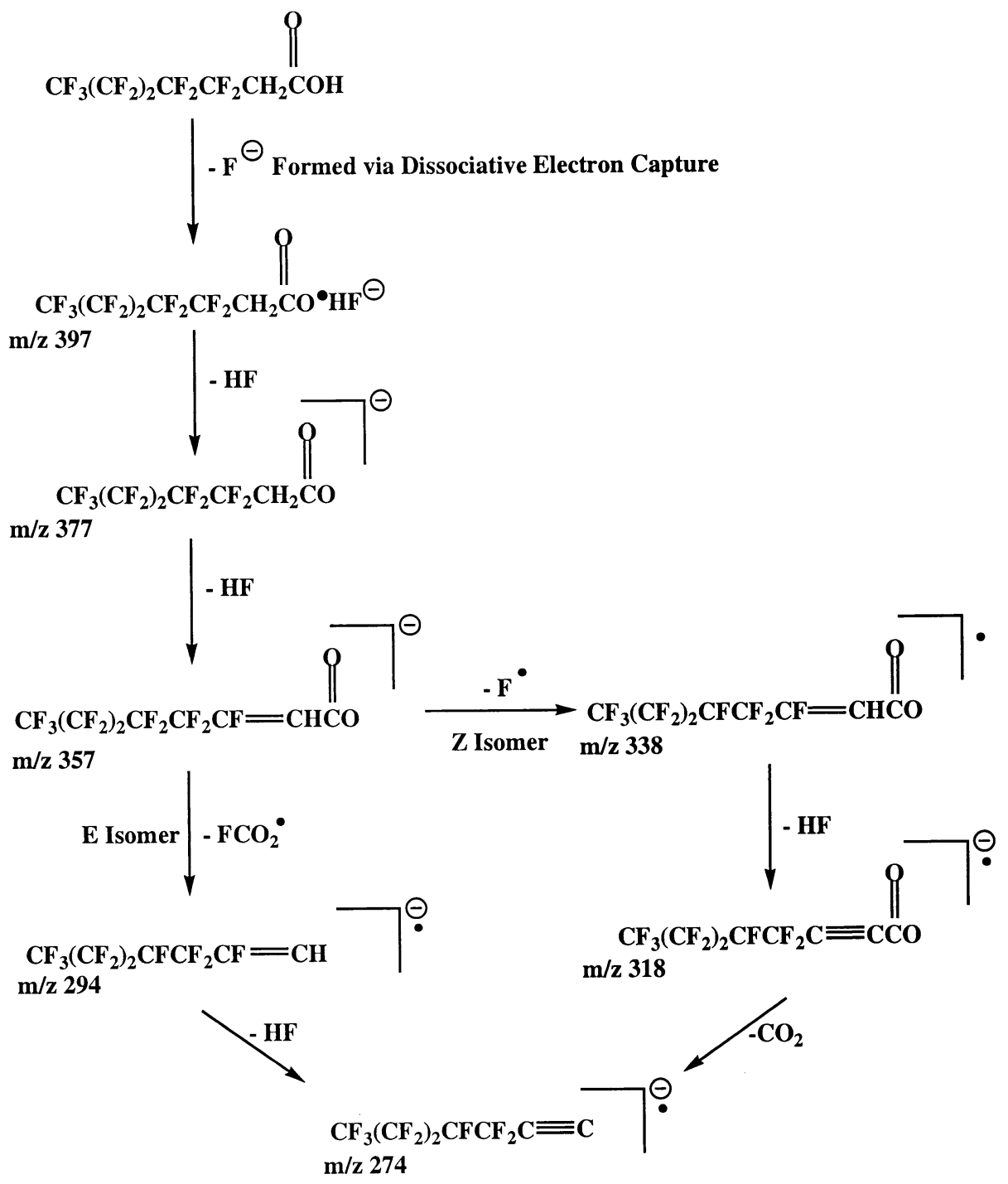

Scheme 4. Proposed fragmentation channels of the telomer acids.

$\mathrm{CH}_{4}$, allowed for the fragmentation of the fluorocarbon chain. It is hypothesized that this is a result of an alteration in the structural geometry of the molecule upon complexation with $\mathrm{NH}_{4}^{+}$. Indeed, this has been observed to be the case for perfluorooctanesulphonate. When protonated, this molecule has a geometry in which the sulfonate moiety is folded back across the fluorocarbon portion of the molecule. When the sulfonate is lithiated, replacement of the $\mathrm{H}^{+}$for a $\mathrm{Li}^{+}$ion, a change in molecular geometry is observed. In this geometry the sulfonate becomes linear with the rest of the molecule [29]. As is often the case with $\mathrm{NH}_{3} \mathrm{CI}$, the alcohol and the $\alpha, \beta$-unsaturated acids lead only to more complex spectra and the complexation of molecular species.

\section{Conclusions}

Due to the interesting geometries which partially fluorinated compounds adopt, the fragmentation pat- terns which are observed appear to be quite different than that which would be predicted from comparison with their hydrocarbon counterparts. Partial hydrogenation would appear to assist the molecular breakdown of fluorinated molecules. The length, and hence degree of fluorination, of the fluorinated alkyl "tail" of the molecule would appear to alter its physical properties. In particular, it can be stated that as a general rule, increased $-\mathrm{CF}_{2}-$ groups within a linear alkane results in increased stability. From the results obtained, it has been shown that fluorination of the hydrocarbon chain has a significant effect on thermodynamically governed processes of degradation and that environmental processes that rely upon the physical properties of the molecule may be significantly affected by the degree to which the molecule is fluorinated. Furthermore, changes in these properties may not be predictable based upon trends seen for smaller molecules, due to radical changes in the molecule's geometry. 

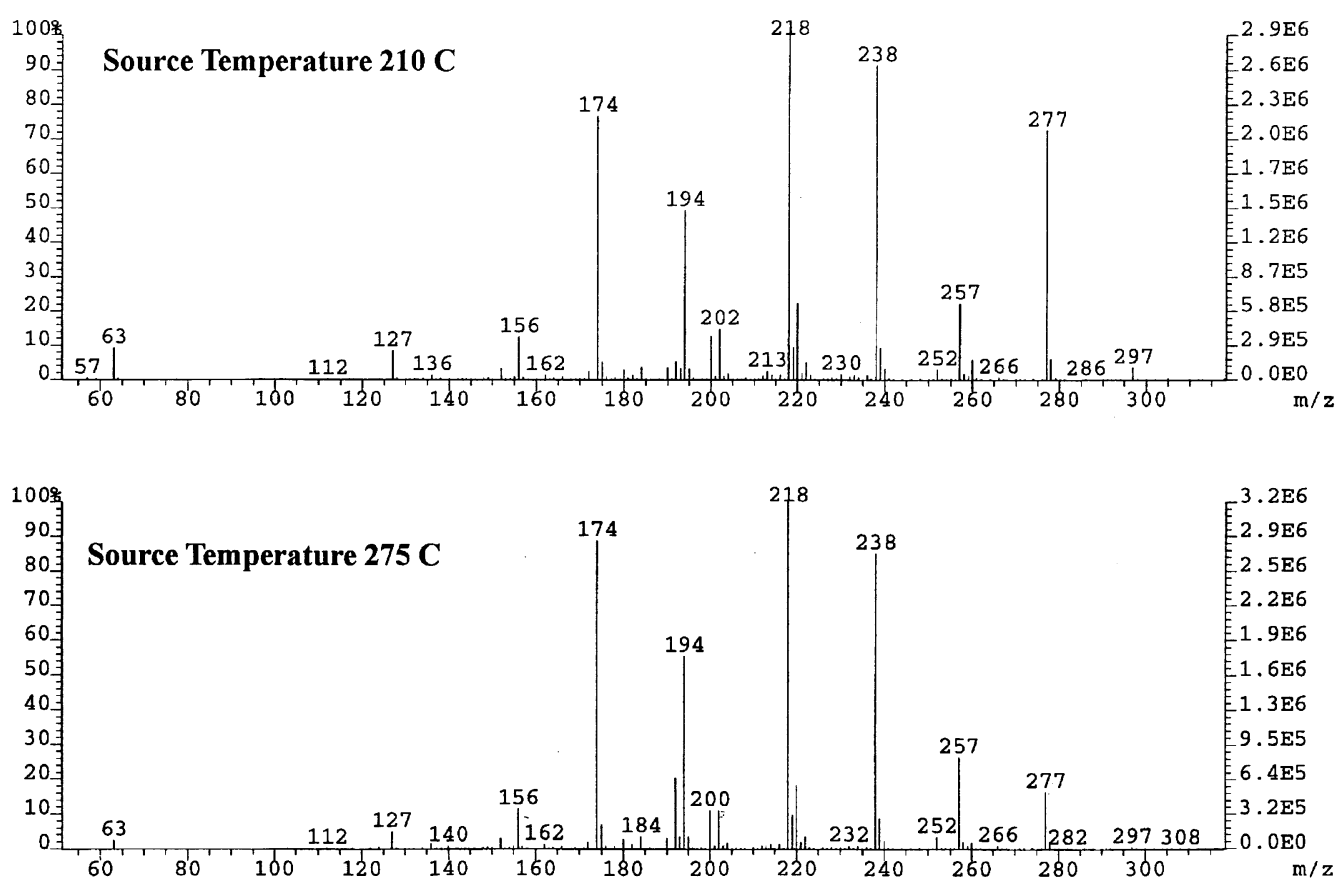

Figure 9. The effect of temperature on the fragmentation pathways (NCI) of the telomer acids. The $4: 2$ acid (m.w. 278) is given as an example.

\section{Acknowledgments}

This work was supported in part by a Strategic Project Grant from the National Sciences and Research Council of Canada (NSERC). The Telomer Research Program (TRP) also provided partial funding for this project. The authors acknowledge the following people who assisted in obtaining mass spectra and/or had very useful suggestions for this manuscript; Dr. Alex Harrison, Dr. Alex Young, Dr. Jon Martin, Ms. Naomi Stock, and Mr. Dan Mathers. This work in part was developed and carried out in the ANALEST facility at the University of Toronto, kindly supported by Perkin Elmer Canada, Analytical Instruments Division.

\section{References}

1. Ellis, D. A.; Hanson, M. L.; Sibley, P. K.; Shahid, T.; Fineberg, N.A.; Solomon, K.R.; Muir, D. C. G.; Mabury, S. A. The Fate and Persistence of Trifluoroacetic Acid and Chloroacetic Acid in Pond Waters. Chemosphere 2001, 42, 309.

2. Ohmori, K.; Kudo, N.; Katayama, K.; Kawashima, Y. Comparison of the Toxico Kinetics Between Perfluorocarboxylic Acids with Different Carbon Chain Lengths. Toxicology 2003, 2-3, 135.

3. Martin, J. W.; Mabury, S. A.; Solomon, K. R.; Muir, D. C. G. Dietary Accumulation of Perfluorinated Acids in Juvenile Rainbow Trout. Environ. Toxicol. Chem., 2003, 22, 189. (b) Martin, J. W.; Mabury, S. A.; Solomon, K. R.; Muir, D. C. G. Bioconcentration and Tissue Distribution of Perfluorinated Acids in Rainbow Trout (Oncorhynchus mykiss). Environ. Toxicol. Chem., 2003, 22, 196.

4. Holloway, J. H. Fluorine, High-Tech Element for the Next Century. J. Fluor. Chem. 2000, 104, 3.

5. Schlosser, M. Parameterization of Substituents: Effects of Fluorine and Other Heteroatoms on $\mathrm{OH}, \mathrm{NH}$, and $\mathrm{CH}$ Acidities. Angew. Chem. Int. Ed. Eng. 1998, 37, 1496.

6. Smart, B. E. Fluorine Substituent Effects (on Bioactivity). J. Fluorine Chem. 2001, 109, 3.
7. Wang, J.; Ober, C. K. Solid State Crystalline and Liquid Crystalline Structure of Semifluorinated 1-Bromoalkane Compounds. Liq. Cryst. 1999, 26, 637.

8. Smart, B. E. Molecular Structure and Energetics. VCH Publishers: Deerfield Beach, FL, 1986, pp 141-186.

9. Kannan, K.; Newsted, J.; Halbrook, R. S.; Giesy, J. P. Perfluorooctanesulfonate and Related Fluorinated Hydrocarbons in Mink and River Otters from the United States. Environ. Sci. Technol. 2002, 36, 2566.

10. Hansen, K. J.; Johnson, H. O.; Eldridge, J. S.; Butenhoff, J. L.; Dick, L. A. Quantitative Characterization of Trace Levels of PFOS and PFOA in the Tennessee River. Environ. Sci. Technol. 2002, 36, 1681.

11. Kannan, K.; Hansen, K. J.; Wade, T. L.; Giesy, J. P. Perfluorooctane Sulfonate in Oysters Crassostrea virginica, from the Gulf of Mexico and the Chesapeake Bay, USA. Arch. Environ. Con. Tox. 2002, 42, 313.

12. Martin, J. W.; Muir, D. C. G.; Moody, C. A.; Ellis, D. A.; Kwan, W. C.; Solomon, K. R.; Mabury, S. A. Collection of Airborne Fluorinated Organics and Analysis by Gas Chromatography/ Chemical Ionization Mass Spectrometry. Anal. Chem. 2002, 74, 584 .

13. Kannan, K.; Franson, J. C.; Bowerman, W. W.; Hansen, K. J.; Jones, J. D.; Giesy, J. P. Perfluorooctane Sulfonate in FishEating Water Birds Including Bald Eagles and Albatrosses. Environ. Sci. Technol. 2001, 35, 3065.

14. Giesy, J. P.; Kannan, K. Global Distribution of Perfluorooctane Sulfonate in Wildlife. Environ. Sci. Technol. 2001, 35, 1339.

15. Moody, C. A.; Kwan, W. C.; Martin, J. W.; Muir, D. C. G.; Mabury, S. A. Determination of Perfluorinated Surfactants in Surface Water Samples by Two Independent Analytical Techniques: Liquid Chromatography/Tandem Mass Spectroscopy and F-19 NMR. Anal. Chem. 2001, 73, 2200.

16. Mabury, S. A.; Crosby, D. G. F-19 NMR as an Analytical Tool for Fluorinated Agrochemical Research. J. Agri. Food Chem. $1995,43,1845$. 
17. Ellis, D. A.; Martin, J. W.; Muir, D. C.G.; Mabury, S. A. Development of an F-19 Method for the Analysis of Fluorinated Acids in Environmental Water Samples. Anal. Chem. 2000, 72, 726 .

18. Napoli, M.; Krotz, L.; Conte, L.; Seraglia, R.; Traldi, P. MassSpectrometric Studies on Some F(CF2)N(CH2)MH Semifluorinated Alkanes. Rapid Commun. Mass Spectrom. 1993, 7, 1012.

19. Napoli, M.; Krotz, L. Scipioni, A; Seraglia, R;; Traldi, P. Mass Spectrometry of Some C6F13-Compounds and their C6H13Analogs. Rapid Commun. Mass Spectrom. 1993, 7, 789.

20. Carbini, M.; Conte, L.; Gambaretto, G.; Catinella, S.; Traldi, P. Mass Spectrometry of Some Fluorinated Alcohols. Org. Mass Spectrom. 1992, 27, 1248.

21. Tajima, S.; Ueki, M.; Tajima, S.; Sekiguchi, O.; Shigihara, A. Unimolecular HF Loss from the Molecular Ions of Fluorophenols and Fluoroanilines. A "ring walk" Mechanism of a Fluorine Atom. Rapid Commun. Mass Spectrom. 1996, 10, 1076.

22. Begley, P.; Foulger, B.; Simmonds, P. Femtogram Detection of Perfluorocarbon Tracers Using Capillary Gas Chromatography-Electron Capture Negative Ion Chemical Ionization Mass Spectrometry. J. Chromatogr. 1988, 445, 119

23. Fielding, H. C. In Organofluorine Surfactants and Textile Chemicals; Banks, R. E., Ed.; Ellis Horwood Ltd.: Chichester, 1979; pp 214-234.

24. Achilefu, S.; Mansuy, L.; Selve, C.; Thiebaut, S. Synthesis of $2 \mathrm{H}, 2 \mathrm{H}$-Perfluoroalkyl and 2H-Perfluoroalkenyl Carboxylic Acids and Amides. J. Fluorine Chem. 1995, 70, 19.

25. Egger, K. W.; Cocks, A. T. Homopolar and Heteropolar Bond Dissociation Energies and Heat of Formation of Radicals and Ions in the Gas Phase. II. Relation Between Structure and Bond
Dissociation in Organic Molecules. Helv. Chim. Acta. 1973, 56, 1537.

26. Hoskin, P. R.; Jones, M.; Sandford, G.; Turner, L. Negative Ion Mass Spectrometry of Highly Fluorinated Compounds. 1. Perhalogeno-Pyridine Derivatives. Rapid Commun. Mass Spectrom. 2000, 14, 91.

27. Caldwell, G.; Kebarle, P. The Hydrogen-Bond Energies of the Bihalide Ions $\mathrm{XHX}^{-}$and $\mathrm{YHX}^{-}$. Can. J. Chem. 1985, 63, 1399.

28. Mihalick, J. E.; Gatev, G. G.; Brauman, J. I. Electron Photodetachment Spectroscopy of Solvated Anions: $\mathrm{RO} \cdot \mathrm{HF}^{-}$or $\mathrm{ROH} \cdot \mathrm{F}^{-}$. J. Am. Chem. Soc. 1996, 118, 12424.

29. Erkoc, S.; Erkoc, F. Structural and Electronic Properties of PFOS and LiPFOS. J. Mol. Struct. Theochem. 2001, 549, 289.

30. Von Werner, K.; Wrackmeyer, B. C-13-NMR Studies of Polyfluorinated Hydrocarbons, Carboxylic Acid Derivatives, Alcohols, and Ethers. J. Fluorine Chem. 1981, 19, 163.

31. Von Werner, K.; Wrackmeyer, B. O-17-NMR Study of Polyfluorinated Alcohols and Ethers. J. Fluorine Chem. 1986, 31, 196.

32. Heni, M.; Illenberger, E. The Unimolecular Decomposition of the Fluoroethylene Radical Anions Formed by Electron Attachment. J. Electron Spectroscop. Relat. Phenom. 1986, 41, 453.

33. Sauers, I.; Harman, G. A Mass-Spectrometric Study of Positive- and Negative-Ion Formation in an SF6 Corona.1. Sources of Sulfur-Fluoride Ions. J. Phys. D Appl. Phys. 1992, 25, 761.

34. Harrison, A. G. Chemical Ionization Mass Spectrometry. CRC Press, 1992, 125-129.

35. Stock, N. L.; Ellis, D. A.; Deleebeek, L.; Mabury S. A., unpublished.

36. Eisele, F. L.; Hanson, D. R. First Measurements of Prenucleation Molecular Clusters. J. Phys.Chem. A 2000, 104, 830-836. 